\section{SECOMP: A program for computing simple effects and comparisons in a factorial design}

\section{FRED D. RIBICH and NERELLA V. RAMANAIAH Southern Illinois University, Carbondale, Illinois 62901}

After performing the overall analysis of variance, the researcher is usually interested in testing several planned and/or post-hoc comparisons for interpreting his data. Program SECOMP was written to compute tests of simple effects and user-specified comparisons for completely randomized designs involving up to three factors (fixed effects only) and an equal number of subjects in all cells.

Specifically, this program is capable of testing simple main effects. simple interaction effects. simple, simple main effects, comparisons. and simple main effects of comparisons of the following types (Keppel, 1973: Kirk, 1\%8):

1. Simple main effect of $\mathbf{A}$ at $\mathbf{b}_{\mathbf{j}}$.

2. Simple interaction effect of $A B$ at $c_{k}$.

3. Simple, simple main effect of $\mathbf{A}$ at $\mathbf{b} c_{\mathbf{j} k}$ :

4. A comp.

5. Acomp $\times$ B.

o. $A_{\text {comp }} \times B C$.

7. Simple main effect of $\mathbf{A}_{\text {comp }}$ at $\mathbf{b}_{\mathbf{j}}$.

8. Simple, simple main effect of $A_{c o m p}$ at $b c_{j k}$.

The user specifies the analyses to be done by preparing a program control card for simple effects, or a program control card for comparisons, or both. Comparisons may be orthogonal or nonorthogonal. or tests for trend depending on the coefficients that the user specifies on the program control card.

For each comparison or simple effect tested. the program computes the $F$ ratio and its corresponding probability level necessary to make planned tests of the effect. For post-hoc testing. the observed $F$ ratios can be tested for significance using standard procedures (Keppel, 1973; Kirk, 1968).

Input. Four program control cards precede the data: a problem title card, design parameters card, simple effects card, and data format card. The data is read according to the user-specified format and should be arranged in cell order with the subscript of the last factor changing fastest. Data may be on cards, tape, or disk. Any number of comparison cards may follow the data, each specifying the factor on which the comparison is to be made, the type of comparison and the coefficients defining the comparison. This sequence may be repeated for additional problems (e.g., analyzing different dependent variables).

Output. A table summarizing the parameters specified for the problem is printed first. For each comparison or simple effects analysis, the source of variation, sum of squares, degrees of freedom, mean square. $F$ ratio, and probability level are given in tabular form. The coefficients defining each comparison are also printed, as well as the error term for the particular design. The cell sums or means may also be printed.

Restrictions. The number of factors in the design must not exceed three and there must be an equal number of subjects in each cell. The maximum number of levels of each factor is eight; however. this limit may be easily modified by changing a small number of program statements.

Computer and language. The program is written in FORTRAN IV and was developed on an IBM $370 / 158$ with virtual memory. The core requirement is $128 \mathrm{~K}$ and the compilation time is approximately $17 \mathrm{sec}$. Execution time for analysis of a 3 by 3 by 2 factorial design with $\mathrm{n}=15$ requesting 12 simple effect tests and 16 comparisons was $1.2 \mathrm{sec}$.

Availability. Program, test data and sample output listings and instructions are available free of charge. A limited number of source decks are available and may be obtained for the cost of mailing. Address requests to Fred D. Ribich, Department of Psychology, Southern Illinois University at Carbondale. Carbondale. Illinois 62901

\section{REFERENCES}

KePPEL. G. Design and analysis: A researcher's handbook. Englewood Cliffs. N. J: Prentice-Hall, 1973.

KIRK. R. E. Experimental design: Procedures for the behavioral sciences. Belmont. California: Brooks/Cole, 1968. 